\title{
Cultura material, espaço doméstico e musealização*
}

\section{Material culture, domestic space and musealization}

\author{
VÂNIA CARNEIRO DE CARVALHO \\ Museu Paulista da Universidade de São Paulo \\ Parque da Independência, s/n Ipiranga \\ São Paulo. SP. CEP 04218-970 \\ vcarvalh@usp.br
}

RESUMO Este artigo procura demonstrar, por meio de uma experiência concreta e ainda em curso, como a curadoria, orientada pela pesquisa, pode renovar as práticas de coleta, documentação e exposição de acervos em museus históricos. O estudo de caso fundamenta-se em discussões conduzidas no campo da cultura material e que identificam o espaço doméstico como um lugar fértil para a incorporação das formas de distinção social e de gênero por meio do uso de objetos. A estreita relação entre materialidade e categorias sócio-culturais aponta para o museu como uma instituição estratégica no fomento de estudos dessa natureza.

Palavras-chave estudos de gênero, espaço doméstico, museus

ABSTRACT This paper attempts to demonstrate, through a concrete and still active practice, how a curatorship characterized by research may redefine

* Artigo recebido em: 04/07/2011. Autor convidado. 
collecting, documenting and exhibiting practices of the collections in historical museums. The case study is based on debates about material culture identifying the domestic environment as a fertile field for the embodiment of social and gender distinctions through objects. The close relationship between materiality and sociocultural categories marks museums as strategic institutions in promoting this kind of study.

Keywords gender studies, domestic space, museums

O presente artigo parte dos resultados de pesquisas empreendidas desde 1997 e que tratam da produção de identidades sociais e de gênero por meio do uso de objetos e espaços domésticos na cidade de São Paulo. ${ }^{1}$ Tais pesquisas foram concebidas e tiveram o seu desenvolvimento associadas às práticas curatoriais exercidas no Museu Paulista da USP desde 1989. ${ }^{2}$

A partir de constatações que a pesquisa nos tem trazido sobre as relações entre cultura material e espaço doméstico, foi possível rever criticamente a forma de coleta institucional de acervo nesta área de estudo, bem como estabelecer critérios de captação de novos acervos. Procuraremos demonstrar como os interesses no campo da cultura material determinaram não apenas o universo documental a ser coletado, mas a forma de processá-lo nos nossos bancos de dados. Igualmente, o núcleo de questões desenvolvido na pesquisa foi retomado e ampliado para dar lugar a uma proposta de exposição intitulada Morar Paulistano. ${ }^{3}$ Com base em uma

1 CARVALHO, Vânia Carneiro de. Gênero e artefato: o sistema doméstico na perspectiva da cultura material. São Paulo, 1870-1920. São Paulo: Editora da Universidade de São Paulo/Fapesp, 2008; CARVALHO, Vânia Carneiro de e LIMA, Solange Ferraz de. Individuo, género y ornamento en los retratos fotográficos, 1870-1920. In: AGUAYO, Fernando e ROCA, Lourdes. (orgs.) Imágenes e investigación social. 1ª. ed. México: Instituto Mora, 2005, v.1, p.271-291.

2 Em 25 de agosto de 1893 o Monumento do Ypiranga é destinado a abrigar o Museu do Estado, criado em 1890 e em 28 de agosto, o Museu do Estado passa a ser denominado Museu Paulista. Ver cronologia em Às margens do Ipiranga, 1890-1990: exposição do centenário do edifício do Museu Paulista da USP. São Paulo: Museu Paulista, 1990. Sobre a trajetória do Museu Paulista ver MORAES, Fábio Rodrigo de. Uma coleção de história em um museu de ciências naturais: o Museu Paulista de Hermann Von Ihering. Anais do Museu Paulista: história e cultura material, São Paulo, Nova Série, janeiro-junho, v.16, n.1, p.203-233, 2008; BREFE, Ana Cláudia Fonseca. O Museu Paulista: Affonso de Taunay e a memória nacional, 1917-1945. Anais do Museu Paulista: história e cultura material, São Paulo, Nova Série, v.10/11, 2005; MAKINO, Miyoko. A construção da identidade nacional: Afonso de E. Taunay e a decoração do Museu Paulista (1917-1937). Anais do Museu Paulista: história e cultura material, São Paulo, Nova Série, v.10/11, 2003; ELIAS, Maria José. Museu Paulista: memória e história. São Paulo: USP, 1996. (História, Tese de doutorado); O historiador Ulpiano Bezerra de Meneses, professor emérito do departamento de História da Faculdade de Filosofia, Letras e Ciências Humanas, foi o responsável pela reformulação do perfil e funções do Museu Paulista a partir de sua direção em 1989. Ver seu plano diretor em MENESES, Úlpiano Toledo Bezerra de. Plano Diretor. São Paulo: Museu Paulista, 1990 (ms).

3 Curadoria e Pesquisa: CARVALHO, Vânia Carneiro de, (coordenação executiva); LIMA, Solange Ferraz de e MARINS, Paulo César Garcez, (assistentes de curadoria); SOARES, Shirley Ribeiro, (projeto museográfico); BOGUS, Ricardo Nogueira, (documentação e coleta de acervos); ALMEIDA, Adilson José de, RIBEIRO, Ângela Maria Gianeze, SANTOS, Tatiana Vasconcelos dos, GUSMÃO, Vagner e ALENCAR, Michelle de Oliveira (atividades de ação educativa); ABELEIRA, Denise Cristina Carminatti Peixoto; SANTOS, Maria da Glória Cruz dos e MARTINS, Geórgia Carolina Carvalho, (conservação); PAULA, Teresa Cristina Toledo de, PETRELLA, Yara Ligia Melo Moreira, SPIGOLON, Sônia Maria e HERGERT, Ina, (equipe de conservação preventiva); LOURENÇO, Dalva, CRUZ, He- 
concepção de curadoria museológica em que a pesquisa e o acervo são o eixo orientador das demais atividades curatoriais - coleta, documentação e difusão - pretendemos demonstrar como tais articulações vêm ocorrendo de maneira solidária na experiência aqui relatada.

No entanto, antes da apresentação do processo curatorial envolvendo a pesquisa sobre espaço doméstico e gênero é forçoso primeiro justificarmos porque o recorte temático é relevante, e porque nos parece conveniente tratá-lo a partir da plataforma que convencionamos chamar de cultura material, ou seja, a partir do estudo das dimensões (e não somente das fontes) materiais da vida social. Em segundo lugar, para que se compreenda o conjunto do processo curatorial, apresentaremos uma síntese das questões e algumas conclusões que a pesquisa nos trouxe e que têm sido retomadas, ainda que de maneira exploratória, para a exposição.

\section{Cultura material e espaço doméstico, situando a abordagem}

Como as diferenças sociais e de gênero são constituídas no e pelo uso cotidiano de espaços e objetos domésticos? A questão já tem quatro décadas, e sua pertinência foi demonstrada por Bourdieu no estudo The Berber house or the world reversed publicado em 1970. ${ }^{4}$ Desde então, tal questão vem mantendo sua importância, especialmente quando aplicada ao contexto das sociedades capitalistas, especialmente àquelas integradas de maneira periférica ao mercado mundial, como é o caso do Brasil. A questão, apesar de simples, ergue-se sobre vários pressupostos teóricos. Ela é fruto de uma longa discussão interdisciplinar sobre o papel da cultura material na vida social. Miller circunscreveu este debate às diferentes formas de se compreender a relação entre sujeito e objeto. ${ }^{5}$ De fato, em torno desses dois polos giraram e ainda giram as mais relevantes discussões sobre a materialidade.

A primeira delas teve início ainda no século XIX, quando Marx combateu o idealismo hegeliano com o conceito de práxis. Para ele a transformação do sujeito social dependia da sua capacidade de transformar o mundo material por meio da produção. Ainda que focado no ciclo produtivo, quando hoje o interesse se desloca para o consumo, o estabelecimento da interdependência entre sujeito e objeto recusava a natureza ilusória da materialidade, própria do idealismo, para atribuir-Ihe um papel ativo na construção deste sujeito. ${ }^{6}$ É fato que desdobramentos da teoria marxista iriam restringir o

Ienilda Aparecida, OLIVEIRA, Izabel Santos, JACOB, Luiz Carlos, BAPTISTA, Núcia Maria de Oliveira, OLIVEIRA, Vera de, (comunicação visual); FIDALGO, Christine May Kaufman, RODRIGUES, Alessandra Roberta, (patrocínio; programa caixa de adoção de entidades culturais patrocínio e fundo de pesquisas do Museu Paulista).

4 BOURDIEU, Pierre. The Berber house. In: LAWRENCE-ZÚÑIGA, Denise e LOW, Setha M. The anthropology of space and place: locating culture. New Jersey: Blackwell Publishing, 2003, p.131-141.

5 MILLER, Daniel. (ed.) Materiality. London: Duke University Press, 2005, p.1-50.

6 MILLER, Daniel. (ed.) Materiality, p.1-50. 
papel da materialidade aos seus usos ideológicos. Seria preciso desvendar ou transcender o mundo das coisas para se chegar à compreensão de sistemas de valores ou conjunto de comportamentos do sujeito. Neste caso, a materialidade se apresentaria como uma máscara da realidade.

Mas, se à materialidade era negada a sua força de agenciamento, outros modelos de compreensão da cultura material inverteram o peso entre os termos sujeito e objeto. Em abordagens criticadas como funcionalistas, adaptativas ou cientificistas, ${ }^{7}$ o objeto era valorizado na sua dimensão pragmática, que determinava o seu modo de apropriação. A reação a tais modelos ficou conhecida como virada simbólica ou linguística.

A nova abordagem, que se estabeleceu pioneiramente na antropologia, com Lévi-Strauss e Clifford Geertz, teve ampla adesão nas ciências humanas. ${ }^{8}$ Buchli destaca os trabalhos de Mary Douglas, Arjun Appadurai, Pierre Bourdieu, Baudrillard, Barthes e a Escola dos Annales como fundamentais para o enfoque da cultura material como sistemas simbólicos. ${ }^{9}$ As estruturas humanas cognitivas gerariam as estruturas sociais, as relações culturais e sociais se estabeleceriam como formas de comunicação efetivadas por meio de sistemas de objetos. A materialidade foi compreendida como o suporte arbitrário de estruturas semelhantes à linguagem, onde seus termos estariam impregnados de sentidos. Por meio do modelo da linguística, desenhado por Saussurre, as categorias sociais - decalcadas e significativamente organizadas nos sistemas de objetos, como uma sintaxe geral - foram entendidas como ausências e presenças ou como combinações binárias, tais como aparecem nos trabalhos sobre indumentária americana de Sahlins, sobre mobiliário moderno de Baudrillard, ou sobre alimentação de Douglas, para citar alguns clássicos. ${ }^{10}$

Com fortes variações, as abordagens da cultura material como um sistema discursivo, mesmo quando afastadas as ambições de atemporalidade e universalidade estruturalistas, enfatizaram o caráter homogeneizante e incorpóreo dos fenômenos culturais. Pensamento e razão suplantaram a materialidade, a experiência e o específico. Se voltarmos ao binômio sujeito e objeto, a balança pende novamente para o primeiro - o sujeito - visto como uma abstração. A materialidade seria a representação de algo que não está presente. A decorrência de tal raciocínio é o desprezo pela fisicalidade, já que ela não é mais que o suporte da representação. ${ }^{11}$

7 BOIVIN, Nicole. Material cultures, material minds. The impact of things on human thought, society, and evolution. Cambridge: Cambridge University Press, 2008, p.10.

8 LAYTON, Robert. Structuralism and Semiotics. In: TILLEY, Chris et alii. (eds.) Handbook of material culture. London: Sage, 2008, p.35

9 BUCHLI, Victor. The material culture reader. Oxford, New York: Berg, 2002.

10 SAHLINS, Marshall. Cultura e razão prática. Rio de Janeiro: Zahar, 1979, p.199; BAUDRILLARD, Jean. O sistema de objetos. São Paulo: Perspectiva, 1993; DOUGLAS, Mary. Food as a system of communication. In: In the active voice. London: Routledge, 1982, p.82-124.

11 TILLEY, Christopher. Objectification. In: TILLEY, Chris et al. (eds.) Handbook of material culture, p.9; BOIVIN, Nicole. Material cultures, material minds, p.31-81. 
Para os fenomenologistas, não se trata de questionar a existência do sentido, mas o modo como ele se constitui. A experiência de being-inthe-world não separa mente e corpo, nem a percepção e a consciência acontecem perante um mundo livre de sentidos. E o sujeito encarnado ("incorporado" como Merleau-Ponty assinalou) que, entrando em relação com os objetos, entende o mundo já como sentido. A produção de sentido é intrínseca à experiência. ${ }^{12} \mathrm{Em}$ vez de discordar do fato de que a matéria representa, procurou-se demonstrar que os sentidos não são arbitrários. Fundamentados pela experiência, os sentidos seriam motivados pelas propriedades materiais do mundo sensível e constituídos não como combinações significativas, mas como metáforas. ${ }^{13}$

Ao se retomar o binômio sujeito-objeto, vê-se que várias são as tentativas de romper com raciocínios em que um dos termos é passivo e o outro ativo. As noções de agenciamento, como querem Latour e Gell, ${ }^{14}$ mutualidade, como Paul Graves-Brown apresenta a questão, e affordance, como quer Gibson, representam o esforço de muitos estudiosos em encontrar o melhor equilíbrio possível para a relação sujeito-objeto. ${ }^{15}$ Colocado de outra forma, trata-se hoje de deslocar a atenção do binômio sujeito-objeto para a ação desencadeada neste encontro.

Boivin oferece um exemplo do poder de agenciamento dos objetos. A autora estudou as casas de barro na zona rural Rajasthan (Índia). A plasticidade deste tipo de matéria-prima permite que pisos e paredes sejam alterados com facilidade e em associação com as mudanças na vida das pessoas. Estas mudanças espaciais não apenas marcam os ritos de passagem domésticos. A metáfora material não é apenas a realização de um conceito de mudança social, sua expressão material, ela é parte da criação do entendimento do conceito de mudança social como alteração física de paredes, aberturas ou fechamentos de passagens, mudanças de cor, de textura, acréscimo ou retirada de ornamentação. Por restringir ou possibilitar a ação das pessoas, o barro exerce um tipo de agenciamento sobre as atividades humanas. ${ }^{16}$

Ao enfatizar os limites e as possibilidades oferecidas pela matéria, procura-se situar o sujeito no meio-ambiente, talvez a melhor expressão seja a de Harrison, "people are not just embodied, but also embodied ecologically". Elucidativos são os exemplos de Alfred Gell que identifica um

12 THOMAS, Julian. Phenomenology and material culture. In: TILLEY, Chris et alli. (eds.) Handbook of material culture, p.47-49.

13 TILLEY, Christopher. Metaphor and material culture. Oxford: Blackwell, 1999; BOIVIN, Nicole. Material cultures, material mind, p.38.

14 GELL, Alfred. Art and agency. Oxford: Oxford University Press, 1998; LATOUR, Bruno. The Berlin key or how to do words with things. In: GRAVES-BROWN, Paul. (ed.) Matter, materiality and modern culture. London, New York: Routledge, 2000, p.10-21.

15 GRAVES-BROWN, Paul. (ed.) Matter, materiality and modern culture, p.4.

16 BOIVIN, Nicole. Material cultures, material minds, p.129-138. 
iconicismo fonológico em algumas línguas dos Papua da Nova Guiné ou associa a vida na floresta Amazônica ao usos mais simbólicos de sentidos como o paladar, olfato e tato e, ao contrário, a vida nas montanhas frias e de pouca vegetação nos Andes com o uso mais intenso da visão. ${ }^{17}$

O esforço parece ser o de superar a dicotomia sujeito e objeto, e fixar como centro de interesse o movimento dialético do processo de objetivação - "In objectification all we have is a process in time by wich the very act of creating form creates consciousness or capacity such as skill and thereby transforms both form and self-consciousness of that which has consciousness, or the capacity of that which now has skill". ${ }^{18}$ É a dinâmica estabelecida não apenas no momento da criação, da produção, mas ao longo do ciclo de vida de objetos e pessoas que interessa. ${ }^{19}$ Ou ainda, o que deve estar em foco é a rede de agentes (humanos e não-humanos) e a relação entre eles. ${ }^{20}$

Segundo Warnier, sujeito e objeto deveriam ser entendidos como uma síntese corpo-objeto-espaço. O sujeito só existiria como corpo indissociável do seu meio ambiente. O processo de apropriação do objeto pelo corpo não é dicotômico, mas uma interiorização do objeto pelo sujeito. Haveria um pensamento corporal que chamaríamos de condutas motoras. A memória corporal seria constituída por estereótipos motores capazes de compactar, simplificar e rotular experiências acumuladas. Reside aí o último ponto que gostaríamos de ressaltar no amplo e heterogêneo debate interdisciplinar que o campo da cultura material nos oferece e que aqui foi tocado apenas no que estrategicamente nos interessa. ${ }^{21}$

Vários autores procuraram identificar na materialidade aquelas características responsáveis pela sua força coercitiva ou subversiva. Sua eficácia parece precisamente residir em sua ação silenciosa, o que Miller chamou de "humildade dos objetos". ${ }^{22}$ A inconsciência seria, então, o modus operandi entre sujeito e objeto. A interação entre corpo e objeto se estabeleceria automaticamente e cotidianamente ou por meio do que Bourdieu denominou como habitus, fenômeno em que as ordens estabelecidas culturalmente seriam inculcadas como uma segunda natureza. ${ }^{23}$ Para Boivin, o poder das metáforas materiais residiria no entendimento não-linguístico do mundo. ${ }^{24}$ Haveria uma consciência corporal alijada da

17 BOIVIN, Nicole. Material cultures, material minds, p.77-80.

18 Rowlands segundo MILLER, Daniel. (ed.) Materiality. London: Duke University Press, 2005 , p.9.

19 TILLEY, Christopher. Objectification. In: TILLEY, Chris et al. (eds.) Handbook of material culture, p.60.

20 Latour and Gell segundo MILLER, Daniel (ed.). Materiality, p.11.

21 WARNIER, Jean-Pierre. Culture matérielle et subjectivation. In: PARLEBAS, Pierre. (coord.) Le corps et le langage: parcours accidentés. Actes de la Journée de L'École doctorale Éducation, langage, societé. Paris: Université Paris V-René Descartes/L'Harmattan, 1999, p.107-117; WARNIER, Jean-Pierre. Construire la culture matérielle. L'homme qui pensait avec ses doigts. Paris: Presses Universitaires de France, 1999.

22 MILLER, Daniel. (ed.) Materiality, p.5.

23 WARNIER, Jean-Pierre. Culture matérielle et subjectivation, p. 107-117; WARNIER, Jean-Pierre. Construire la culture matérielle; FOUCAULT, Michel. Os corpos dóceis. In: Vigiar e punir: história da violência nas prisões. Rio de Janeiro: Vozes, 1977, p.125-152; BOURDIEU, Pierre. A economia das trocas simbólicas. São Paulo: Perspectiva, 1974

24 BOIVIN, Nicole. Material cultures, material minds, p.56. 
consciência cognitiva, de natureza discursiva e verbal, não existindo uma necessária homologia entre a prática discursiva e a prática motriz. ${ }^{25}$ Neste modo silencioso de agenciamento, a cultura material seria também o lugar privilegiado de exercício do poder.

O caminho das discussões sobre a materialidade da cultura, ainda que pontuado brevemente, justifica os recortes da pesquisa. Entendido como um lugar de práticas corporais envolvendo, desde a infância, o uso cotidiano de objetos, o espaço doméstico torna-se um lugar extremamente importante para a constituição das identidades sociais e de gênero. Tradicionalmente, os estudos de interiores seguem dois caminhos opostos. O primeiro, derivado das artes decorativas, dedicou-se à montagem de repertórios de mobiliário, porcelanas e demais artefatos acumulados pela aristocracia e alta burguesia. Tais abordagens, com enfoque nas qualidades formais, tecnológicas e materiais desses artefatos, resultaram em uma história dos estilos. Trilhando um outro caminho, estudos folclóricos se dedicaram ao levantamento da arquitetura e objetos de interiores vernaculares em busca de traços autênticos que mostrassem a cultura local como uma cultura criativa e de resistência, base para a construção de identidades nacionais. ${ }^{26}$

As aspirações universalizantes de uma história dos estilos e as buscas por raízes identitárias regionais e nacionais baseadas na herança vernacular puderam ser revistas por novos enfoques trazidos da sociologia e da antropologia e que iluminaram, especialmente, o entendimento da entrada dos bens de consumo na casa. ${ }^{27} \mathrm{~A}$ demanda por bens de consumo não é reduzida a simples manipulação de mercado, mas é entendida como novas possibilidades de agenciamento desses bens para a construção tensa e instável de formas de autonomia e de subordinação que vão muito além das possibilidades oferecidas pela esfera da produção. ${ }^{28}$

No Brasil, o que denominamos genericamente como "casa moderna" teve sua melhor expressão no palacete, ${ }^{29}$ tipo de residência altamente especializada - áreas públicas segregadas das áreas privadas e de serviço, intermediadas por áreas de transição internas e externas. A especialização e o porte aristocrático herdado de modelos europeus do século XVIII atendiam às aspirações burguesas baseadas no consumo conspícuo e privado

25 WARNIER, Jean-Pierre. Culture matérielle et subjectivation, p.107-117; WARNIER, Jean-Pierre. Construire la culture matérielle.

26 BUCHLI, Victor. The material culture reader. Oxford, New York: Berg, 2002; CLIVE, Wainwright. The romantic interior: the British collector at home. 1750-1850. London: Paul Mellon Centre for Studies in British Art, New Haven: Yale University Press, 1989.

27 GEORGE, Robert St. Home Furnishing and Domestic Interiors. Structuralism and Semiotics. In: TILLEY, Chris et alli. (eds.) Handbook of material culture, p.221-229.

28 MILLER, Daniel. Consumo como cultura material. In: Horizontes Antropológicos, Porto Alegre, v.13, n.28, p.3, julho-dezembro 2007.

29 Sobre os palacetes paulistanos ver CARVALHO, Maria Cristina Wolff de. Bem-morar em São Paulo, 1880-1910: Ramos de Azevedo e os modelos europeus. Anais do Museu Paulista, São Paulo, v.4, p.165-200, janeiro-dezembro 1996; CARVALHO, Maria Cristina Wolff de. Ramos de Azevedo. São Paulo: Edusp, 2000; HOMEM, Maria Cecília Naclério. O palacete paulistano e outras formas urbanas de morar da elite cafeeira: 1867-1918. São Paulo: Martins Fontes, 1996. 
como forma de construção de identidades social e individual. ${ }^{30}$ No entanto, as casas de tradição portuguesa ${ }^{31}$ e aquelas menos abastadas pertencentes aos emergentes segmentos médios puderam abraçar o novo modo de vida por meio do consumo dos objetos de decoração. Para uma parcela da sociedade, adquirir uma nova casa ou reformar a antiga era difícil ou impossível, já o consumo de objetos de decoração e de itens de mobília era mais acessível e por isso tais práticas se tornariam uma das formas primordiais de demonstração de ascensão social. ${ }^{32}$ Para esta população era possível reformar ou incrementar o mobiliário, adquirir peças decorativas ou mesmo confeccioná-las a partir de receitas divulgadas em revistas, em cursos ou a partir da orientação de parentes e amigos mais experientes.

\section{Espaço doméstico e gênero, apresentando as questões}

Ao longo da pesquisa procuramos demonstrar como, em uma sociedade com industrialização incipiente como era São Paulo ao final do século XIX, o incremento dos hábitos de consumo voltados para a produção da casa - equipamentos de trabalho e conforto, a ampliação devastadora do repertório para se mobiliar e decorar ambientes de casas agora especializadas - foi responsável pela construção de identidades sociais e de gênero diferenciadas e que envolveram mudanças no próprio corpo de seus usuários - novas posturas corporais exigidas pelo uso de novos artefatos como o fogão a gás, ${ }^{33}$ pelo uso de espaços públicos ${ }^{34}$ e privados agora regrados por orientações de comportamento e por aparatos como novas peças de indumentária e acessórios pessoais. Observamos o relacionamento

30 A mercantilização dos objetos domésticos e a sua exibição privada e ostensiva marcaram um rompimento com as práticas coloniais, onde a demonstração de posição social privilegiada fazia-se em ocasiões públicas, momentos coletivos marcados pela religiosidade e por uma liberalidade "generosa" do consumo das riquezas individuais. Para a transição das práticas de ostentação ver MARINS, Paulo César Garcez. Através da rótula: sociedade e arquitetura no Brasil, séculos XVII a XX. 1ª.ed. São Paulo: Humanitas/FFLCH/USP, 2001; BORREGO, Maria Aparecida de Menezes. Laços familiares e aspectos materiais da dinâmica mercantil na cidade de São Paulo (séculos XVIII e XIX). Anais do Museu Paulista, São Paulo, v.18, n.1, p.11-41, junho-dezembro 2010; OLIVEIRA, Maria Luiza Ferreira de. Entre a casa e o armazém: relações sociais e experiência da urbanização. São Paulo, 1870-1900. São Paulo: Alameda Casa Editorial, 2005.

31 Caracterizadas por uma baixa capacidade de expressar formalmente a situação social de seu proprietário. Com soluções locais criadas e transmitidas por profissionais anônimos, elas eram usualmente organizadas numa forma simplificada de distribuição frente-fundos e alinhadas com a rua. A diversidade entre as residências tradicionais dava-se muito mais na dimensão, volume e no número de portas e janelas do que nos seus aspectos formais ou tecnológicos ver em CARVALHO, Maria Cristina Wolff de. Bem-morar em São Paulo, 1880-1910: Ramos de Azevedo e os modelos europeus, p.165-200; CARVALHO, Maria Cristina Wolff de. Ramos de Azevedo; HOMEM, Maria Cecília Naclério. O palacete paulistano e outras formas urbanas de morar da elite cafeeira. 1867-1918, p.14.

32 Para a importância da aquisição de imóveis para os segmentos médios ver OLIVEIRA, Maria Luiza Ferreira de. Entre a casa e o armazém.

33 MENESES, Ulpiano T. Bezerra. O fogão da societé anonyme du gaz. Sugestões para uma leitura histórica de imagem publicitária. Projeto História. História e Imagem. Revista do Programa de Estudos de Pós-graduandos em História e do Departamento de História, PUC-SP, São Paulo, n.21, p.105-119, novembro 2000; SILVA, João Luís Máximo da. Cozinha modelo: o impacto do gás e da eletricidade na casa paulistana (1870-1930). São Paulo: EDUSP, 2008.

34 LIMA, Solange Ferraz de. Ornamento e cidade: ferro, estuque e pintura mural em São Paulo, 1870 - 1930. São Paulo, USP, 2001. (História, Tese de doutorado). 
simbiótico entre os objetos domésticos, identidades sociais e de gênero. ${ }^{35}$ A cultura material seria, como vimos acima, a dimensão indissociável de ações, sentidos e valores.

No caso masculino, a relação corpo-objeto regular-se-ia segundo um princípio auto-referencial, que denominamos de personalidade centrípeta e que estimularia o desenvolvimento de uma identidade masculina fortemente individualizadora. ${ }^{36} \mathrm{O}$ que notamos é uma hierarquia entre a figura masculina e seus objetos, em que os atributos destes nunca se sobrepõem àquele, ao contrário, eles servem para desenhar ou qualificar a personalidade.

Para as mulheres, a relação corpo-objeto caracterizaria um tipo de personalidade social centrífuga. A baixa capacidade de individualização feminina decorreria de uma forma extensiva e inespecífica de apropriação do espaço doméstico e, simultaneamente, da suavização e naturalização da retórica feminina nos objetos. A estes dois formatos de identidade de gênero estão associadas funções sociais, padrões corporais, sentidos, valores e ações igualmente diversos.

Julgados apenas pela quantidade, diríamos que a casa de extração burguesa é o reino do feminino. A quantidade de objetos de uso exclusivo masculino é pouca se comparada à acumulação intensa de artefatos domésticos, especialmente aqueles com função decorativa, característica das residências do século XIX. No entanto, a força designativa dos objetos masculinos cria ao seu redor um campo gravitacional que altera o sentido sexualmente indiferenciado de objetos. A própria mulher pode mudar de gênero quando ingressa na órbita estabelecida pelo território masculino, como vemos na descrição de José de Alencar, quando Aurélia, protagonista do romance Senhora, entra no gabinete da casa para receber o tio Lemos, seu tutor. Aurélia precisava armar-se de qualidades masculinas para enfrentar os interesses do tutor e para isso utiliza o escritório, seara do masculino, que permite sua transmutação:

Quem observasse Aurélia naquele momento não deixaria de notar a nova fisionomia que tomara o seu belo semblante e que influía em toda a sua pessoa. Era uma expressão fria, pausada, inflexível, que jaspeava sua beleza, dando-lhe quase a gelidez da estátua. Mas no lampejo de seus grandes olhos pardos brilhavam as irradiações da inteligência. Operava-se nela uma revolução. O princípio vital da mulher abandonava seu foco natural, o coração, para concentrar-se no cérebro, onde residem as faculdades especulativas do homem. ${ }^{37}$

Os objetos domésticos masculinos nos remetem imediatamente ao universo do trabalho intelectual, atividade revestida do mais alto prestígio.

35 CARVALHO, Vânia Carneiro de. Gênero e artefato.

36 É preciso que se diga desde o início que não se trata de uma determinação, mas de uma tendência, portanto, com espaço para a transgressão, a inversão..

37 ALENCAR, José de. Senhora. Porto Alegre: L\&PM Pocket, 1997, p.27. 
As mesas de trabalho, confeccionadas em madeira escura e maciça, com tampos horizontais muito amplos, herdaram a imponência das mesas inglesas utilizadas em bibliotecas eclesiásticas e universitárias do final do século XVIII. ${ }^{38}$ Imagens de homens em escritórios de bancos e de empresas são frequentes na imprensa ou em livros de apresentação dos progressos da cidade.

Às matérias-primas também são atribuídas conotações de gênero. Ao couro, por exemplo, tem sido agregados sentidos que o associam à figura masculina. As cadeiras rígidas, com assento e encosto de couro lavrado migraram dos ambientes religiosos e estatais - onde não apenas predominavam homens, mas onde as lideranças eram prerrogativa masculina - para os ambientes domésticos, onde se tornariam símbolo de poder masculino. Não se trata do couro de arreios, selas, jaquetões, bolsas e acessórios de viagem, que fazia parte do universo do antigo homem paulistano, ou da relação que o couro tinha com a caça, atividade provedora dos caipiras do interior paulista. ${ }^{39}$ As heranças do passado pobre e rural foram substituídas pelo couro refinado e masculino do mobiliário inglês associado à plutocracia inglesa que soubera transformar os hábitos monásticos e rurais da antiga nobreza em verdadeiras exibições de poder e riqueza.

Objetos com funções instrumentais explícitas na sua forma de apresentação são associados ao gênero masculino como é o caso de arquivos, estantes giratórias de livros, instrumentos de escrita (tinteiro, mata-borrão, sinete, abridor de cartas etc.), ventiladores (observáveis nos escritórios domésticos e profissionais). Nos anúncios publicitários e fotografias de estúdio ou impressas em revistas e jornais, as mãos masculinas aparecem somente em função do uso de algum objeto associado ao trabalho intelectual ou ao conforto - cigarro, café, jornal, guarda-chuva, livro.

Os repertórios masculinos são regidos por uma lógica estritamente pessoal. Os livros, os objetos de escritório, os móveis, os acessórios pessoais, os contratos e registros do patrimônio familiar ${ }^{40}$ guardados no cofre, mas também o jogo de jantar herdado e o monograma marcando os objetos apontam para a construção de uma masculinidade voltada para a máxima individualização.

A "síntese corporal" da mulher com o espaço da casa é o oposto daquela que observamos para o homem. ${ }^{41}$ A presença feminina espraia-se pela casa toda, está no embelezamento, na manutenção e na limpeza de todos os espaços, inclusive aqueles considerados estritamente masculinos. Esta

38 GIEDION, Siegfried. La mecanización toma el mando. Barcelona: Gustavo Gilli, 1978, p.295.

39 CÂNDIDO, Antônio. Os parceiros do rio Bonito: estudo sobre o caipira paulista e a transformação dos seus meios de vida. Rio de Janeiro: José Olympio, 1964, p.37.

40 Um exemplo dessa tipologia é o Diário de atividades da fazenda Jardim, situada na cidade de Limeira, Estado de São Paulo. O diário foi produzido pelo seu proprietário Olegário de Abreu Ferraz entre 1894 e 1936. Acervo do Museu Paulista da USP.

41 Para o conceito de síntese corporal ver: WARNIER, Jean-Pierre. Culture matérielle et subjectivation, p.9-15. 
territorialidade alargada, se por um lado poderia significar uma forma de poder ou de reconhecimento social relevante, também nos diz sobre a baixa capacidade de individualização da figura feminina. A integração do corpo feminino com os objetos doméstico é inespecífica. Ao contrário da figura masculina que se faz presente na casa por meio de objetos retoricamente masculinos, a figura feminina se apresenta de forma difusa por toda a casa.

A cobertura feminina é aquela da decoração. Um sistema de toalhas, capas, bolsos, cestos, sacolas, caixas, tampos (a mesa-costureiro, a máquina de costura), vedações (biombos e cortinas) estão presentes na casa. Estes invólucros servem para camuflar a funcionalidade dos objetos, bem como o trabalho feminino envolvido na manutenção da casa. São comportamentos herdados dos modelos de decoração ecléticos e vitorianos, em que se pretende, com os artesanatos domésticos, criar um ambiente agradável, associado a representações idealizadas da natureza, de cenas rurais e da sociedade pré-industrial tratadas de maneira artística. As chamadas artes aplicadas ou artes decorativas são altamente difundidas ao mesmo tempo em que discriminadas como um trabalho de menor importância, porque exercido por mulheres e para o espaço da casa.

A substituição das matérias-primas para a confecção dos trabalhos manuais (da seda para fios de algodão até chegarmos aos trabalhos industrializados em fios sintéticos ou estampados em plástico), bem como a introdução de técnicas de tecelagem artesanal mais acessíveis como o crochê, o tricô, o macramê, o paneaux nos dão provas da penetração social vertical dos valores associados ao aburguesamento da casa. Os trabalhos com agulhas permitiram a reprodução de padrões de ornamentação com diferentes técnicas e matérias-primas. Bordados e rendas podiam ter versões simplificadas, mescladas com partes já produzidas em série pela indústria. Esse conjunto de possibilidades e imitações permitia que famílias remediadas ou mesmo pobres decorassem suas casas por meio de um sistema de coberturas que substituía a ausência de móveis refinados. Tais estratégias facilitaram o comprometimento dessas camadas sociais, antes marginalizadas, com o ideário burguês - cosmopolitismo, asseio, ordem e especialização. Por meio de rendas e bordados as marcações femininas no espaço da casa encontraram opções fáceis e acessíveis.

A prática do artesanato pressupõe como ponto de partida uma relação orgânica entre corpo e objeto, onde o sujeito, reproduzindo técnicas e padrões transmitidos de geração a geração, exerce pleno domínio sobre cada etapa de seu trabalho, sendo a agulha, o tear ou a tesoura de costura extensões do próprio braço. O trabalho manual doméstico insere a mulher nesse universo simbólico que guarda raízes com um mundo estável, agora representado pela casa, e que se contrapõe à fluidez da experiência urbana.

Analisando o contexto norte-americano oitocentista, Beverly Gordon observa a ausência de distinções entre casa e corpo feminino. Tal indistinção 
se dá por semelhança entre trabalhos manuais confeccionados para a casa e aqueles produzidos como adereço pessoal. A fusão do corpo feminino com a casa, herança da experiência vitoriana, seria fruto de uma reação às mudanças promovidas pela industrialização e urbanização, e resultado do aprofundamento das diferenças entre homens e mulheres. ${ }^{42}$ Juliet Kinchin encontrou na literatura inglesa do século XIX textos que apontavam a harmonia entre a indumentária da mulher e as cores de ambientes da casa. ${ }^{43}$ Observou a presença da mesma matéria-prima para a confecção de roupas femininas e estofados da sala, além de um vocabulário comum para descrever móveis e atributos da feminilidade. Os mesmos procedimentos estão largamente documentados nas revistas femininas que orientam estas práticas de decoração de si e da casa paulistana. Especificamente, os trabalhos em tecido ou linha, rendas e bordados foram largamente utilizados para criar superfícies visuais homogêneas que uniram indistintamente o sujeito feminino aos artefatos e espaços da casa. Flores e rendas estão presentes nos vestidos, acessórios e mesa. O conjunto harmonioso inclui sempre a protagonista que se funde ao cenário no momento do evento através de uma coreografia corporal devidamente prescrita para a ocasião.

A intercambialidade do corpo feminino com o cenário da casa tem como consequência a baixa capacidade de individualização da mulher. Esta ação difusa é feita por meio de um repertório de temas muito próprio. Trata-se de representações extraídas de um universo natural filtrado e reelaborado pela arte.

Os modelos artísticos utilizados por mulheres na produção do artesanato doméstico são flores, folhas, animais miniaturizados, considerados agradáveis ao olhar. A fusão entre corpo feminino e uma natureza frágil e delicada mostra-se no uso frequente de metáforas com flores. Em todos os manuais encontramos referência a elas. As mulheres são exaustivamente representadas em fotografias ao lado de vasos de flores, portando buquês, com roupas estampadas com motivos florais. Manuais e artigos de revistas ensinavam a confecção de flores de papel, utilizadas para enfeites de toda sorte. A presença de flores naturais na casa era praticamente obrigatória. Recém-colhidas do jardim, as flores enfeitavam o interior das salas como um sinal da presença da mulher. As flores estavam nas estampas das cortinas, nas almofadas, nos estofados das salas, nos acessórios pessoais e nos objetos de guardar. Eram utilizadas para descrever qualidades e sentimentos femininos, perfumavam as roupas brancas, estavam nos centros

42 GORDON, Beverly. Victorian fancywork in the American home: fantasy and accommodation. In: MOTZ, Marilyn F. e BROWNE, Pat. Making the American home. Middle-Class women \& domestic material culture 1840-1940. Bowling Green/Ohio: Bowling Green State University Popular Press, 1988, p.50.

43 KINCHIN, Juliet. Interiors: nineteenth-century essays on the masculine and the feminine room. In: KIRKHAM, Pat. (ed.) The gendered object. Manchester/New York: Manchester University Press, 1996, p.18. 
das mesas, na forma dos objetos decorativos e figuravam como os motivos prediletos das rendas e dos bordados.

A síntese entre o corpo feminino e os objetos domésticos acontece de uma maneira específica, diferente da masculina - ação irradiadora, que cobre cada objeto da casa com um véu de feminilidade, atinge a engrenagem doméstica, inclusive seus empregados, seus ritos sociais, familiares e o seu próprio corpo.

Esta forma diferenciada de interação implica funções igualmente diferenciadas para a mulher no ambiente doméstico. A função de mediadora está em oposição à personalidade marcante e forte que se espera dos homens. A inteligência vista como tipicamente feminina era aquela cujas características dessem conta da complexidade de relações que a mulher deveria administrar, tanto no meio familiar quanto no social. A valorização da intimidade e o enriquecimento das relações sociais concorreram para a constituição do papel feminino de mediadora. Esta habilidade, tão cultuada pelos manuais de aconselhamento, torna-se fundamental perante a diversificação das relações sociais, que exigiam da família um esforço conjugado para levar a cabo negociações econômicas e afetivas mais dinâmicas e intensas a partir do final do século XIX. Mesmo para aquelas famílias que não participavam da efervescência da vida mundana, a função feminina de mediadora tornou-se essencial para articular um conjunto complexo de desejos e personalidades dos filhos, marido, parentes, agregados, empregados e amigos mais próximos.

\section{Pesquisa e museu, exercendo a curadoria - A aura dos objetos históricos}

A pesquisa sobre gênero e espaço doméstico nasceu no interior da linha de pesquisa Cotidiano e Sociedade, concebida para o Museu Paulista em 1990. As questões da pesquisa, brevemente apresentadas acima, serviram como condutoras do levantamento e análise que fizemos do acervo museológico. Era-nos claro que o museu não funcionava apenas como um lugar que continha fontes documentais de interesse. Ao longo da existência do museu, era sabido que a maioria dos acervos ligados à constituição dos espaços domésticos paulistanos ingressara na instituição por meio de doações. Ao lado de curadorias ativas voltadas para os acervos ditos históricos, como foi o caso de Taunay, ${ }^{44}$ noções subliminares sobre o que deveria ser conservado em um Museu de História guiaram tanto curadores

44 Taunay, diretor do museu entre 1917-1945, era o mentor do projeto de criação no Museu Paulista de uma narrativa visual e material evocativa dos personagens e acontecimentos formadores da Nação e do papel central de São Paulo neste processo. Seu projeto definiu o perfil das coleções institucionais e dotou o museu das condições necessárias para o exercício de sua função pedagógica. 
quanto doadores. Uma dessas noções era certamente aquela que via o museu como um lugar privilegiado para a pedagogia das massas. Simultaneamente, para os doadores, o museu era um meio de transcender os limites da vida doméstica - cotidiana, perecível e estritamente privada - para se atingir a vida pública, tornar-se memória hegemônica. ${ }^{45}$ Assim, doar ao museu é uma maneira de apropriação do espaço público e de resignificação dos objetos doados. Por meio do museu e na forma de objeto museológico (testemunho, vestígio), as elites paulistanas puderam garantir seu ingresso nas representações históricas da sociedade. Décadas depois, a imagem do Museu Paulista como um museu de elite certamente emergiu desse processo que está na base da formação de muitas de suas coleções. Foi nessa perspectiva que nos interessou investigar a tipologia de objetos ingressos no museu como doação e que poderiam ter marcas de gênero. Se o ato de doar é socialmente significativo, as noções de gênero foram constituídas por meio do ato e não previamente.

Com base no critério de seleção do que merecia a publicização por meio do museu, pudemos observar que em algumas tipologias de objetos prevalecia o pertencimento a homens. Era o caso de objetos pessoais cujo maior interesse não era o objeto em si, mas quem os havia utilizado - carteiras de identidade, passaportes, títulos de eleitor, brevês, certificados, nomeações, certidões, licenças de trânsito, diplomas (de titulação acadêmica, de premiação, de maçonaria, de homenagem, de associação), carteiras, caixas de óculos, itens de indumentária e mobiliário, mas também medalhas, troféus, distintivos, botons de eventos públicos e acontecimentos políticos, comendas, entre outros. Nas doações que o Museu Paulista recebe, até hoje, o titular masculino faz questão de encaminhar documentos que comprovem o seu desempenho físico, profissional e político. Nesse contexto, portanto, são comuns as medalhas, condecorações, troféus, diplomas, certificados e peças de homenagem. ${ }^{46}$

O interesse biográfico está muito claro no conjunto de canetas doadas ao Museu Paulista e que são o símbolo da criatividade masculina que encontra no trabalho intelectual a sua expressão máxima. São canetas feitas de metal e pedrarias nobres, que pertenceram a proeminentes figuras da política e da cultura nacional - Prudente de Moraes, Campos Sales, Pedro de Toledo, Américo Brasiliense, Wenceslau Brás, Bernardino de Campos, Santos Dumont e Altino Arantes. Não há uma só peça que tenha pertencido

45 CARVALHO, Vânia Carneiro de e LIMA, Solange Ferraz de. Cultura material e coleção em um museu de história: as formas espontâneas de transcendência do privado. In: FIGUEIREDO, Betânia Gonçalves e VIDAL, Diana Gonçalves. (org.) Museus: dos gabinetes de curiosidades à museologia moderna. Belo Horizonte: Argvmentvm/ CNPq, 2005, p.85-110.

46 As coleções do Museu Paulista estão repletas de documentos "masculinos" dessa natureza como diplomas de titulação acadêmica, diplomas de sócio efetivo de associações, diplomas comemorativos, diplomas de medalha, diplomas de maçonaria, nomeações, passaportes, brevês, certificados, certidões, títulos de eleitor, carteiras de identidade, apenas para citar alguns exemplos levantados nas coleções textuais. 
a uma mulher. A caneta de ébano e prata que pertenceu ao ex-Presidente Campos Sales vem com a etiqueta do doador pregada à caixa "serviu na assinatura do termo do 1 casamento civil realizado no Brasil"; o mesmo procedimento se repete com a pena em ouro e diamantes, cuja etiqueta diz "caneta com que Prudente de Moraes assinou a pacificação do Rio Grande do Sul"; em 1917, Wenceslau Brás utilizou uma bela caneta em forma de pena, feita de ouro, brilhantes e esmeraldas, para assinar o Ato de Guerra contra a Alemanha. Em 1920, Altino Arantes assinou com a caneta a ata de lançamento da pedra fundamental do Palácio da Justiça. Uma caneta de ébano e prata foi usada por ministros para a assinatura do termo de Proclamação da República em 16 de novembro de 1889. A caneta de Prudente de Moraes, utilizada para a assinatura da Constituição Federal de 24 de fevereiro de 1891, foi deixada em testamento para seu filho Pedro de Moraes Barros. Em 1916, com a mesma caneta assinaram-se os papéis de seu casamento e, em 1941, de sua filha Maria Moraes Barros. Observemos que, neste último caso, por contato físico, objetos masculinos utilizados na vida pública serviram para dignificar atos da vida privada.

Objetos masculinos musealizados como representantes da atividade intelectual de seus usuários são também as máquinas de escrever, os estojos de escritório e os óculos. Na Revista Industrial de Jules Martin, de 1900, entre as diversas pranchas ilustradas com estabelecimentos comerciais e paisagens urbanas de São Paulo, os óculos e os pince-nez aparecem ao lado de objetos considerados do universo masculino como ferramentas de dentista ou junto a binóculos, microscópios, barômetros e bússolas. ${ }^{47}$ Um confronto entre óculos femininos e masculinos no acervo do Museu Paulista nos informa sobre o uso (e valorização) diferenciado da visão entre homens e mulheres. Entre uma dezena de óculos depositados nessa instituição, a maioria pertenceu a personalidades ilustres, todas masculinas. O contraponto é um face-à-main ${ }^{48}$ feminino, utilizado para leituras rápidas, como podemos observar em anúncios de lojas e de moda em que figuram mulheres utilizando os óculos com haste. ${ }^{49}$ Tal fato não significa que as mulheres não usassem óculos, ${ }^{50}$ significa que eles não eram considerados femininos. A expressão do olhar e os traços delicados do rosto eram elementos importantes para uma concepção natural de beleza, que não poderia ficar comprometida pela necessidade de uso intenso da visão, tal inversão de hierarquias significava o comprometimento da feminilidade. Schwartz demonstrou como os aparelhos de surdez só foram utilizados por mulheres

47 Lojas Boticão Universal e La Pendule Suisse - Relojoaria e Bijouteria Maurice Grumbach \& Cia. Pranchas em MARTIN, Jules. Revista Industrial. São Paulo: s.c.p., 1900 (obra artesanal, acomodada em caixa de madeira, contendo fotografias originais e desenhos colorizados). Acervo do Museu Paulista da USP.

48 Óculos que substitui o suporte para o nariz e orelhas por haste utilizada por uma das mãos.

49 Casa Allemã. In: A Cigarra, 08 de dezembro de 1915, s.n.p. A Moda. In: Revista Feminina, fevereiro de 1919, p.16.

50 Se observarmos os retratos do século XIX e início do século XX, veremos muitos homens de óculos, mas também mulheres, em menor número e sempre mais velhas. 
quando a tecnologia possibilitou a sua miniaturização e o entendimento das variações tonais, ou seja, quando estes puderam auxiliar na manutenção dos atributos considerados femininos - a camuflagem da tecnologia e a interpretação do som para além do reconhecimento das palavras. ${ }^{51}$

Outra categoria de objetos masculinos que se sobressaiu no levantamento dos acervos do museu foram os bustos escultóricos. A partir das indicações fornecidas pelo acervo e estendidas a documentos iconográficos e textuais pudemos verificar como os bustos eram formas recorrentes de constituição da identidade masculina nas comemorações e decoração públicas que penetraram na vida doméstica e lá se tornaram referências da presença do chefe da casa. ${ }^{52}$ Nos corredores da Secretaria da Fazenda e do Thesouro do Estado de São Paulo, os bustos exibem-se em pedestais de madeira. Uma variação do busto escultórico são os pratos comemorativos ou de homenagem como o exemplar que integra o acervo do Museu Paulista fabricado na região de Moselle, na França, e que traz a foto-pintura do presidente Washington Luís. Esta tipologia de natureza honorífica encontrase bem representada no acervo do Museu Paulista. Trata-se de bustos e efígies masculinas, na sua grande maioria de personalidades brasileiras - busto do Marechal Floriano Peixoto, Barão de Rio Branco, Washington Luís, Antonio da Silva Prado, Victor Hugo, Santos Dumont, Oswaldo Cruz, General Jardim, efígie de Pedro de Toledo, Vítor Meireles, Barão de Rio Branco, entre outros. ${ }^{53}$ Foi possível, a partir da identificação da relevância desta tipologia para as questões de gênero, coletar o busto de mármore, de uso doméstico, de Benjamin Jafet, fundador da Fiação Tecelagem e Estamparia Ypiranga Jafet, doado ao museu em 2009.

Quando nos voltamos para os acervos de indumentária e acessórios pessoais que pertenceram a mulheres, encontramos objetos estritamente ligados à vida privada. Estes objetos carregam representações iconográficas que nos remetem ao mesmo temário que, em outras fontes, pudemos identificar como atribuídos à figura feminina. Tais objetos trazem aplicadas à sua superfície imagens de flores, ramagens, pássaros, borboletas, cenários de paisagens bucólicas, cenários exóticos do oriente e imagens oníricas. O uso de materiais orgânicos é frequente - leques de penas de avestruz, tucano e pavão; joias e relicários utilizando sementes, cabelos e escaravelhos, folhas secas. A recorrência das mesmas categorias de motivos ornamentais (arranjos

51 SCHWARTZ, Hillel. Hearing aids: sweet nothings, or an ear for an ear. In: KIRKHAM, Pat. (ed.) The gendered object. Manchester: Manchester University Press, 1996, p.43-59.

52 A apropriação que se fez, a partir do Renascimento, do caráter público do busto escultórico tornou-o uma forma de representação apropriada ao homem. A inspiração nos modelos do classicismo investia-os de imponência, um monumento em escala doméstica. A matriz mais próxima dos bustos escultóricos está no estilo Império, criado na França durante o governo de Napoleão. Nele foram utilizados emblemas da Roma Imperial, entre eles os bustos de guerreiros com armadura, que simbolizavam poder e fama. O monocromatismo e a perenidade do metal e da pedra associados ao estilo da estatuária greco-romana coincidiam com o gosto masculino por objetos de ostentação pouco ornamentados.

53 A única exceção é uma efígie da Princesa Isabel de 1946. 
florais, pássaros, ramagens) e de matérias-primas e técnicas (plumas, sedas, rendas, estampas pintadas a mão) numa grande diversidade de objetos como vidros de perfume, caixas de joias, chapéus, almofadas, trabalhos manuais, estofados, tapetes, abajures, toalhas, apenas para citar alguns, mostra-nos como se efetivam noções como harmonia, bom gosto, elegância, delicadeza, recorrentes na literatura como definidoras do ser feminino.

\section{A coleta de acervos segundo critérios da pesquisa}

Apesar do interesse histórico que podem suscitar acervos constituídos por meio de doações estimuladas pela natureza ideológica do museu, a condução da pesquisa se dá por meio de documentação maciça, coletada segundo critérios tipológicos ou associada às questões formuladas pelo curador ao longo de sua investigação. Foi graças à documentação maciça de retratos que atualmente o museu possui que foi possível investigar como as problemáticas do espaço doméstico e gênero se davam em uma produção voltada para a representação pública do indivíduo. Foi possível controlar, entre milhares de exemplares fotográficos, a incidência de retratos masculinos em relação aos femininos, foi também possível comparar poses, cenografias, interações entre homens e mulheres nas fotografias de casais, famílias e amigos. ${ }^{54}$

Da mesma forma, as questões pertinentes à identidade masculina e feminina levaram-nos aos anúncios publicitários e à forma de representação do masculino e do feminino na propaganda. Ao longo da pesquisa consultamos o Acervo Histórico Mappin. ${ }^{55}$ Este acervo é constituído por uma série documental de 60 mil anúncios da loja, produzidos entre 1913 e 1985. Com a falência da loja em 1999, ano em que tínhamos consultado a documentação, tal acervo entrou em situação de risco de se perder ou deteriorar. Frente à necessidade do museu de investir na formação de séries documentais, foi negociada a doação dos documentos para a instituição, o que ocorreu em 2008.

A coleção de peças publicitárias reunidas no "Acervo Histórico do Mappin" veio enriquecer uma categoria de documentos de natureza prescritiva que teve seu interesse renovado por pesquisadores interessados em compreender como a população paulistana, especialmente aquela distante dos ambientes da corte no Rio de Janeiro e das cidades europeias, conseguiu realizar suas primeiras experiências com interiores finamente decorados.

54 CARVALHO, Vânia Carneiro de e LIMA, Solange Ferraz de. Individuo, género y ornamento en los retratos fotográficos, p.271-291.

55 A loja Mappin foi inaugurada como loja de departamento, em São Paulo, em 1913, fruto da sociedade entre a Mappin \& Webb e John Kitching. A Mappin \& Webb já existia em São Paulo, desde 1912 e, no Rio de Janeiro, desde 1911, porém como casa de cristais e prataria. A primeira loja surgiu em 1774, em Shefield, ao norte da Inglaterra. Sua especialidade eram presentes finos. Em Londres, foi fornecedora da casa real. Na América Latina, a primeira loja Mappin \& Webb foi criada em Buenos Aires (Argentina), ainda no final do séc. XIX. Em 1985, a loja possuía 8.500 funcionários atuando em 70 departamentos. A loja faliu em 1999, com 13 lojas e 5.000 funcionários. 
Além das casas particulares abertas para leilão, das salas de espera e recepção de ambientes comerciais como hotéis, ateliês de pintura e fotografia, restaurantes, clubes e consultórios médicos, as imagens de interiores de residência exibidas nas lojas e publicadas em jornais e revistas serviram como referência de gosto, valor de modernidade, forma de distinção social, ensinando aos seus consumidores como se comportar, como se vestir, como decorar e mobiliar suas casas.

A coleção Mappin mostrou-se uma fonte rica para o estudo das propostas de decoração da casa, além disso ela também nos informa sobre a disseminação de tais valores no meio popular. A loja praticava preços e apresentava produtos usualmente consumidos por famílias mais abastadas, no entanto, a loja publicava regularmente anúncios nos principais jornais e revistas da cidade, inclusive em línguas estrangeiras como o inglês, o francês, o árabe, o italiano, o japonês e o húngaro, almejando atingir potenciais consumidores nos grupos de imigrantes. Mantinha serviços de encomenda pelo correio, telefone e fazia entregas a domicílio. Lançava campanhas em momentos especiais como carnaval e temporadas líricas e promovia liquidações de verão e inverno. ${ }^{56} \mathrm{Em}$ São Paulo, a loja Mappin pode ser entendida como um dos polos difusores de novos padrões de gosto e hábitos relacionados à intensificação do consumo. Ao lado dos manuais de orientação doméstica, de moda, de etiqueta, de educação dos filhos, exercia a função de compensar a ausência de memória e de tradição referentes às novas práticas de vida que prosperavam na cidade..$^{57}$

A vinda dos documentos da loja Mappin permite também demonstrar que o museu pode e deve buscar acervos independentemente de tipo de suporte. A um museu voltado para a dimensão material da vida social, não interessam exclusivamente as fontes tridimensionais, mas qualquer fonte documental que possa informar sobre o modo como a materialidade da vida em sociedade age sobre as relações entre pessoas, ou seja, como vimos acima, partimos do princípio de que as relações sociais não são imateriais, ao contrário, pessoas e objetos estão imbricados na dinâmica da vida. Assim, se objetos são privilegiados em um museu, fontes iconográficas e textuais também têm lugar em instituições museológicas e devem ser articuladas aos estudos de objetos.

\section{Curadoria e documentação de acervos}

Com a vinda da documentação do Mappin uma nova frente de pesquisa foi aberta. Três alunas inscritas no Programa de Iniciação Científica da

56 ALVIN, Zuleika e PEIRÃO, Solange. Mappin, setenta anos. São Paulo: Ex-Libris, 1985, p.66-79.

57 PADILHA, Márcia. A cidade como espetáculo: publicidade e vida urbana na São Paulo dos anos 20. São Paulo: Annablume, 2001, p.25. 
Universidade trabalham hoje com a documentação. ${ }^{58}$ Seus projetos estão voltados para a comparação dos preços praticados pela loja em comparação com o mercado, as estratégias de alargamento das vendas para segmentos sociais menos abastados, os novos produtos apresentados e o modo como a publicidade introduzia novos itens de consumo e com isso introduzindo novos hábitos de higiene, de alimentação, de conforto, de decoração etc. Para qualquer uma destas questões, o tratamento quantitativo da documentação é imprescindível. Assim, o banco de dados institucional se desenvolve para atender tais demandas nascidas na pesquisa. Não se trata apenas de dar acesso visual aos itens de um acervo, mas de permitir que perguntas sejam feitas às bases de dados de modo que se receba uma resposta da massa documental, como, por exemplo, quais eram os tecidos mais recorrentes para a indumentária masculina ou feminina, ou quantos itens considerados de preço acessível foram introduzidos pelo Mappin, ou ainda, qual o papel do Mappin na ampliação do repertório de consumo do paulistano.

Nesta perspectiva, com as alunas de iniciação científica e com o analista de sistemas do museu, Luciano Antônio Beraldo, foi desenvolvido um banco de dados que integra o Programa de Catalogação dos Acervos. Este banco deve sistematizar informações importantes para as pesquisas em curso, ao mesmo tempo em que colocará a documentação à disposição de outros pesquisadores interessados e do público em geral. O banco de dados reúne não só os dados mais imediatos de identificação do documento e sua reprodução imagética, mas contém a descrição e o vocabulário controlado associado a um glossário, que identifica o tratamento dado às figuras humanas (com a aplicação de descritores utilizados para os retratos), e novos vocabulários para a identificação e descrição de tipos de tecidos, tipos de indumentária (forte da loja nos seus primeiros anos) e repertório de móveis e objetos oferecidos à venda.

A pesquisa mostrou também a necessidade de se rever o modo de documentação da entrada de novas coletas no museu. Se, por um lado, pudemos identificar objetos que pertenceram a homens e mulheres, por outro, não foi possível distinguir, nos conjuntos depositados no museu, os documentos que ingressavam por escolha dos curadores daqueles que foram selecionados pelos doadores. Tais distinções são fundamentais para entendermos como o doador constrói memórias sexuadas.

Recentemente, entramos em contato com uma possível doadora em que as questões de gênero se mostram em toda a sua complexidade. Uma historiadora paulistana mostrou-nos um conjunto de objetos que pertencera

58 LOBATO, Nathalia Theophilo. Cultura material e consumo na cidade de São Paulo: a publicidade da loja Mappin 1913-1920. Início: 2010; SANTOS, Tamires Martins dos. Cultura material e consumo na cidade de São Paulo: a publicidade da loja Mappin, 1921-1930. Início: 2011; SANTOS, Raissa Monteiro dos. Anúncios publicitários e consumo na cidade de São Paulo: Mappin Stores, 1931 e 1940. Início: 2011. São todas alunas de Iniciação Científica atuando no Programa de pesquisa em cultura material do Museu Paulista. 
a seu pai, falecido em uma cidadezinha no interior do Estado. Ela trouxera os objetos para sua residência, em São Paulo, para guardá-los como recordação de seu pai. Este acumulara, em uma espécie de pequenas coleções e objetos de afeto, abotoaduras, moedas, cédulas monetárias, vários retratos $3 \times 4 \mathrm{~cm}$ (sobras de produção fotográfica para documentos pessoais), revólveres em miniatura, bilhetes e cartas, a última bituca de cigarro que seu pai havia fumado antes de ser levado para um hospital de isolamento na década de 1940 por estar com sífilis. Nestes conjuntos também havia correntes com santinhos, pulseiras, brincos que a filha pensa terem pertencido à sua mãe, falecida antes do pai, e às irmãs, quando meninas. Junto a estes objetos ela também encontrou uma carteira de couro com vários recortes de jornal e de revista com imagens ${ }^{59}$ de mulheres em lingeries e roupas de banho, que deveriam funcionar como uma espécie de ativador erótico, pueril aos nossos olhos, mas nem por isso inusual para homens que não se utilizavam de internet, filmes, revistas ou fotografias especializadas no ramo eróticopornográfico. Por sua vez, a filha retirou os objetos dos pequenos vidros e caixas em que se encontravam, eliminou objetos quebrados considerados por ela sem interesse e a este conjunto somou objetos de uso pessoal do pai como duas navalhas para barbear, uma bala de revólver, as ferramentas de ferreiro, profissão que o pai exercera quando mais jovem, um distintivo policial, também lembrança de cargo exercido. Temos, então, dois momentos importantes de seleção - aquele em que o pai guarda objetos, inclusive de uso feminino, como as joias e bijuterias da esposa e filhas e um segundo momento em que a filha revê e remonta o conjunto feito pelo pai, para fazer o seu próprio, que, por sua vez, segue critérios de representação da figura paterna para ela. Notamos que este tipo de coleção nada tem a ver com os objetos que encontramos e analisamos no acervo do museu. Não há aqui qualquer movimento da doadora para publicizar representações privadas do masculino como foram o caso das canetas de políticos, bustos, óculos, máquinas de escrever, escrivaninhas etc., o interesse parte do curador, que identifica nesta prática um desdobramento das questões identificadas na pesquisa. Esse tipo de seleção jamais iria para um museu sem o incentivo de um curador interessado em documentar seleções de objetos familiares. Michelle Alencar demonstrou, ao analisar um processo de doação para o museu, como a doadora escolheu os objetos que pertencera a seu pai tendo em vista suas noções de História, algumas delas ligadas a grandes temas já consagrados e disseminados como História da Imigração, História da Industrialização, História dos Estilos etc. ${ }^{60}$

59 Fotografias impressas e uma representação em desenho impresso.

60 ALENCAR, Michelle de Oliveira. Biografia de uma coleção: de objeto a documento histórico. Uma nova abordagem de doações de acervos familiares. São Paulo: Museu Paulista da USP, 2008. (Iniciação Científica, Programa de pesquisa em cultura material). 
O que dizer então dos objetos associados ao trabalho feminino doméstico. Tipologias que podem nos informar sobre as mudanças de mobilização do corpo no trabalho da casa - como é o caso dos objetos manuais e mecânicos e sua passagem para as versões eletrificadas ${ }^{61}$ (que propagandas como as do Mappin podem nos informar e fornecer um roteiro de coleta) - ou o repertório de alimentos in natura para aqueles industrializados que rótulos, embalagens, livros de receita podem nos informar. São fontes ainda consideradas de segunda linha por aqueles interessados nas qualidades estéticas ou técnicas como critério de seleção dos objetos considerados dignos de musealização.

Igualmente, observamos uma ausência de caracterizações sociais e historicização dos objetos doados. Faz-se necessário estabelecer um protocolo (um roteiro) de informações que devem ser coletadas junto com os objetos como a quem pertenceram, não só inicialmente, mas ao longo do tempo; como foram utilizados; a quais objetos estavam associados. Mais uma vez, o trabalho de Michelle Alencar procurou documentar a casa de onde saíram as doações, pois percebeu-se que a doadora tinha organizado sua residência basicamente com o mobiliário e os objetos decorativos e de uso de seus antepassados. Entender os critérios que permitiram à doadora decidir entre o que ficava e o que deveria ir para o museu pareceu fundamental. Assim, trata-se igualmente de documentar a história social dos objetos e não apenas as informações que o doador entende que devam ser consideradas. Hoje o curador age passivamente perante as declarações do doador, tendo apenas o cuidado de registrá-las. Faz-se igualmente necessário levantar os dados que situam socialmente os doadores e as gerações ascendentes - profissões, casamentos, filhos, lugar de moradia ao longo do tempo etc. Parecem informações óbvias e simples, mas que não são sistematicamente levantadas pelos museus de história, em parte pela ausência de funcionários que possam se ater com mais vagar nesta fase da coleta e ao registro da vida institucional destas coleções. ${ }^{62} \mathrm{~A}$ necessidade de um protocolo de doações tem incentivado pesquisadores a se dedicar ao tema no Museu Paulista. ${ }^{63}$

A qualificação da matéria-prima do conhecimento histórico se dá por meio da documentação do acervo e, evidentemente, por meio da sua conservação. O vínculo necessário da curadoria com a pesquisa já é prérequisito para agências de financiamento. Foi um projeto de pesquisa e o

61 ARRUDA, Márcia Bomfim de. Objetos turbulentos, territórios instáveis: uma história das representações dos aparelhos elétricos no espaço doméstico (1940-1960). São Paulo: PUC-SP, 2010. (História, Tese de doutorado).

62 A vida dos objetos continua a existir depois de sua musealização. Devem ser, portanto, documentadas as trajetórias institucionais. Referimo-nos a participações em exposições, publicações, filmes, publicidade, trabalhos de pesquisa, etc.

63 Michelle de Oliveira Alencar. Biografia de uma coleção. MACIEL, Ana Carolina. Cultura material. Percursos autobiográficos: entrevistas com doadores do Museu Paulista (USP). Pós-doutorado com bolsa Fapesp iniciado em 2010 (supervisão de Cecília Helena de Salles Oliveira). 
histórico de pesquisas que justificaram vários patrocínios da FAPESP de equipamentos para infraestrutura do museu. O mais recente está voltado para a aquisição de mobiliário e embalagens com a finalidade de expandir as áreas de reservas técnicas do museu, ${ }^{64}$ implantação ainda em curso e que beneficiará toda a sua estrutura de salvaguarda, além de permitir novas coletas de acervo.

\section{Curadoria e exposição}

Um dos maiores desafios que enfrenta o curador de história é a exposição. Não pretendemos condenar exposições tipológicas ou biográficas, mas buscar um caminho que seja coerente com a perspectiva aqui apresentada. Se a pesquisa e o acervo foram escolhidos para ser os eixos estruturantes da curadoria no museu, definindo as políticas de coleta e de documentação, não há por que deixar de fora a exposição. O que nos interessa, portanto, é, por meio da exposição, reconstruir tridimensionalmente e visualmente as problemáticas de pesquisa, ${ }^{65}$ para que estas possam ser oferecidas à interpretação para um público amplo e heterogêneo. O museu completa a sua missão, estendendo as ações educativas para além das salas de aula a fim de oferecer a quem se interessar a oportunidade de refletir sobre processos históricos e, por consequência, sobre a sua própria situação de agente social hoje.

Fala-se muito na pluralidade de funções que a exposição cumpre afetiva, lúdica, informativa, social (no sentido mais amplo possível, como experiências de pertencimento, memória e nostalgia) e, finalmente, reflexiva. De fato, a exposição deveria oferecer todas estas facetas da experiência cultural, mas como imaginar que tais experiências possam ocorrer de maneira desinteressada, sem engajamento do visitante, especialmente a última, a experiência de reflexão, portanto, de crítica à sociedade, ao nosso lugar, ao lugar do outro etc.? No entanto, apesar da importância que reconhecemos no ato de apropriação do visitante, restringir-nos-emos no âmbito deste artigo à proposta expositiva, por uma simples razão: é neste momento que o projeto se encontra.

Para uma exposição em que propomos discutir problemas históricos por meio de objetos, o desafio está justamente na sobreposição de funções que estes mesmos objetos assumem no espaço expositivo. De fato, o museu se diferencia por garantir a existência material de documentos tridimensionais e iconográficos, mas é na exposição que se evidencia a

64 Projeto Apoio à Infraestrutura de Pesquisa - Centros Depositários de Informações, Documentos e/ou Coleções Biológicas. Chamada FAPESP 16/2009. Pesquisadora responsável: Cecília Helena de Salles Oliveira.

65 Para compreender o quadro conceitual em que nos apoiamos ver MENESES, Ulpiano T. Bezerra de. Do teatro da memória ao laboratório da História. Anais do Museu Paulista: história e cultura material, São Paulo, v.2, p.9-42, 1994. 
especificidade do museu na produção de conhecimento. Uma pesquisa acadêmica realiza-se com a análise de documentos e a comunicação dos resultados se faz, tradicionalmente, não com a exibição dos documentos, mas por meio da linguagem textual. Na exposição, se não cedemos à tentação de atribuir aos painéis e às legendas a função explicativa que pertence aos objetos, temos de construir com os documentos materiais as convenções visuais e espaciais. Como qualquer forma de comunicação, a exposição trabalha com uma linguagem - justaposições, sobreposições, agrupamentos, ênfases, contrapontos, aproximações etc., mas que são também perceptivas e corporais, em suma materiais e não arbitrárias como o código linguístico. ${ }^{66}$ Ao mesmo tempo, estas convenções são utilizadas de modo a encaminhar inferências sobre o passado, o que significa utilizar os objetos da exposição simultaneamente como documento e como meio de comunicação. Em outras palavras, selecionamos segmentos documentais - atributos materiais mobilizados pela lógica documental do curador - para com eles representar (metaforicamente) dimensões da sociedade segundo, é claro, o enunciado do curador. Desta forma, sugerimos ao visitante que faça um percurso analítico que conduziria às inferências sobre as questões formuladas pelo curador:

O museu histórico coleta, preserva, estuda e comunica documentos históricos. A exposição verdadeiramente histórica é aquela em que a comunicação dos documentos, por sua seleção e agenciamento, permite encaminhar inferências sobre o passado - ou melhor, sobre a dinâmica - da sociedade, sob aspectos delimitados, que conviria bem definir, a partir de problemas históricos. Inferências são abstrações, que não emanam da materialidade dos objetos, mas dos argumentos dos historiadores, referindo-se a propriedades materiais "indiciárias" desses objetos e a informações sobre suas trajetórias. ${ }^{67}$

Ou ainda,

(...) o museu apresenta uma sequência lógica possível entre outras (de objetos), ou seja, uma hipótese narrativa face à pluralidade de outras dissertações igualmente viáveis. A elaboração do discurso expositivo passa por sucessivos exercícios de selecção e síntese aplicados quer sobre os objectos, quer sobre a informação que lhe é associada. ${ }^{68}$

As dificuldades de tal empreitada foram apontadas por Meneses que sugere uma comunicação por camadas, da mais simples à mais comple-

66 DEVALLON, Jean. Comunicação e sociedade: pensar a concepção da exposição. In: MAGALHÃES, Aline Montenegro e BEZERRA, Rafael Zamorano; BENCHETRIT, Sarah Fassa. (orgs.) Museus e comunicação: exposições como objeto de estudo. Rio de Janeiro: Museu Histórico Nacional, 2010, p.25.

67 MENESES, Ulpiano T. Bezerra de. Do teatro da memória ao laboratório da História, p.39.

68 ROQUE, Maria Isabel Rocha. Comunicação no museu. In: MAGALHÃES, Aline Montenegro; BEZERRA, Rafael Zamorano e BENCHETRIT, Sarah Fassa. (orgs.) Museus e comunicação, p.50. 
xa, de modo a atender à heterogeneidade de públicos com capacidades diferenciadas de domínio da convenção visual e espacial da exposição e seus discursos.

No presente caso, tratamos de retomar as questões demonstradas na pesquisa sobre gênero e espaço doméstico associadas a pesquisas correlatas, ${ }^{69}$ porém agora projetadas em um contexto temático e temporal mais amplo. Em uma das três alas expositivas do museu será montada a exposição O Morar Paulistano. Prevista como de longa duração e desenvolvida no interior da linha de pesquisa Cotidiano e Sociedade, a exposição discute, a partir da experiência de decorar e cuidar da casa, a difusão do consumo conspícuo e suas relações com a produção de diferenças sociais e de gênero, com os rituais de recepção e com os trabalhos de manutenção e rotina doméstica.

Não temos condições de aqui descrever todos os módulos expositivos, nem isso nos parece necessário. Para uma demonstração metodológica escolhemos alguns pontos de um dos oitos módulos que compõem a exposição, intitulado Aprendendo o Feminino.

Cinco dos oito módulos expositivos tratam de repertórios ornamentais. Neles, nosso objetivo é demonstrar como, por meio do movimento social de apropriação de repertórios ornamentais temáticos e formais, a sociedade logra a circulação e atualização, em diferentes épocas e segmentos sociais, de práticas de distinção e de construção de identidades sociais e de gênero. A exposição, atuando tanto na linha sincrônica quanto diacrônica, apresenta agrupamentos distintos de objetos. Cada agrupamento possui como princípio a justaposição de objetos com semelhanças formais e temáticas, ${ }^{70}$ ao mesmo tempo em que estes mesmos objetos se diferenciam por suas funções, por suas épocas (1870 até os dias de hoje), por suas matériasprimas e contextos (domésticos, públicos, comerciais, institucionais). Em alguns casos, um agrupamento pode se opor radicalmente a outro.

69 A curadoria conjunta com Solange Ferraz de Lima e Paulo César Garcez Marins foi pensada tendo em vista as afinidades de nossos trabalhos na área. LIMA, Solange. Ornamento e cidade; LIMA, Solange Ferraz de. O trânsito dos ornatos: modelos ornamentais da Europa para o Brasil, seus usos (e abusos?). Anais do Museu Paulista, v.16, p.145-192, 2008; MARINS, Paulo César Garcez. Habitação e vizinhança: limites da privacidade no surgimento das metrópoles brasileiras. In: SEVCENKO, Nicolau. (org.) NOVAIS, Fernando A. (dir.) História da vida privada no Brasil, v.3 (Da Belle Époque à Era do Rádio). São Paulo: Companhia das Letras, 1998, v.3, p.131-214; MARINS, Paulo César Garcez. Moradias dos paulistas: das fazendas às vilas operárias. São Paulo: Centro de Estudos e Pesquisas em Educação, Cultura e Ação Comunitária (CENPEC), 2005; MARINS, Paulo César Garcez. Através da rótula; MARINS, Paulo César Garcez. Vida cotidiana entre os paulistas: moradias, alimentação, indumentária. In: SETUBAL, Maria Alice. (org.) Terra paulista: histórias, arte, costumes. São Paulo: CENPEC/IMESP, v.2, p.89-190, 2004.

70 Há controvérsias sobre a eficácia de tais justaposições como em DEVALLON, Jean. Comunicação e sociedade: pensar a concepção da exposição, p.26. 
Tabela 1

Agrupamento 1

OBJETOS com diferenças de funções, de tecnologia, de morfologia, de épocas, de significados

\begin{tabular}{l|l|l|l|l|l|l|l}
\hline Toucas de & Camisolas & Chapéus & Vestidos de & Almofa- & Toalhas de & Colchas & Toalhas de renda \\
bebê com & femininas & femininos & festa com & das com & mesa com & para camas & de diversos tipos \\
diversos & com diver- & com diver- & diversos & diversos & diversos & com diver- & para decoração \\
tipos de & sos tipos & sos tipos de & tipos de & tipos de & tipos de & sos tipos & de móveis \\
renda & de renda & renda (ar- & renda (ar- & renda (ar- & renda (ar- & de renda & \\
(artesanais e & (artesanais e endesanais e & tesanais e & tesanais e & tesanais e & (artesanais e & \\
industriais) & industriais) & industriais) & industriais) & industriais) & industriais) & industriais) & \\
\hline
\end{tabular}
SISTEMAS EM QUE ESTÃO INSERIDOS

\begin{tabular}{|c|c|c|c|c|c|c|c|}
\hline $\begin{array}{l}\text { Uso infantil. } \\
\text { Vida } \\
\text { doméstica. } \\
\text { Áreas } \\
\text { privadas e } \\
\text { sociais. }\end{array}$ & $\begin{array}{l}\text { Uso } \\
\text { feminino. } \\
\text { Vida domés- } \\
\text { tica. Áreas } \\
\text { privadas. }\end{array}$ & $\begin{array}{l}\text { Uso } \\
\text { feminino. } \\
\text { Vida } \\
\text { pública. }\end{array}$ & $\begin{array}{l}\text { Uso } \\
\text { feminino. } \\
\text { Vida domés- } \\
\text { tica - áreas } \\
\text { sociais. } \\
\text { Vida } \\
\text { pública. }\end{array}$ & $\begin{array}{l}\text { Vida } \\
\text { doméstica } \\
\text { - áreas } \\
\text { sociais. }\end{array}$ & $\begin{array}{l}\text { Vida } \\
\text { doméstica } \\
\text { - áreas } \\
\text { privadas e } \\
\text { sociais. }\end{array}$ & $\begin{array}{l}\text { Vida domés- } \\
\text { tica - áreas } \\
\text { privadas. }\end{array}$ & $\begin{array}{l}\text { Vida doméstica } \\
\text { - áreas privadas } \\
\text { e sociais, desde } \\
\text { as cozinhas até } \\
\text { os espaços mas- } \\
\text { culinos. como o } \\
\text { escritório. }\end{array}$ \\
\hline
\end{tabular}

No quadro acima, que representa um agrupamento em que os objetos se articulam pelo uso da renda, os enunciados que se espera sejam inferidos são os seguintes:

Primeira camada de enunciados:

1. A renda é um artefato feminino.

2. A renda era usada no passado e continua sendo usada até hoje.

3. A renda pode estar tanto no corpo feminino e quanto na casa.

Segunda camada de enunciados:

4. A renda é utilizada em todo lugar, desde a roupa (dentro e fora de casa), a cama até o banquete, por isso ela associa o corpo feminino à casa.

5. As rendas são diferentes, podem ser muito trabalhadas, feitas à mão ou podem ser mais simples, feitas de crochê.

Terceira camada de enunciado:

6. A renda é um objeto que utilizado pela cultura para construir a ideia de feminino em associação à casa.

7. A identidade de gênero é construída também pelos objetos.

Quarta camada de enunciados:

8. A associação da renda a espaços íntimos e sociais da casa e também a espaços externos à casa, levaria ao entendimento de que os objetos que marcam o gênero feminino não são autônomos, mas agem transversalmente, participando (e por isso articulando) sistemas diferentes como a vida doméstica mais íntima à vida pública. Tal articulação levaria a pensar que as obrigações e direitos constituídos em um sistema, no caso o doméstico, podem migrar para outros sistemas ligados à vida pública. 
9. A associação dos tipos de rendas com diferentes épocas e diferentes segmentos sociais provocaria uma discussão sobre as formas de apropriação de um ornamento e seu caminho social ao longo do tempo.

A comparação do agrupamento 1 de objetos com o agrupamento 2, descrito abaixo, amplia o repertório de objetos femininos, inserindo as representações de flores, folhas, insetos e o uso de elementos orgânicos como o cabelo e insetos em artefatos de uso corporal e uso decorativo na casa. Com isso, introduzimos dois novos elementos aos atributos materiais considerados femininos: a natureza, porém tratada na sociedade em questão de forma artística, em que seus elementos são estilizados e suavizados, sem, no entanto, deixar de criar um elo entre a figura feminina e a naturalização de sua condição social e cultural. A mesma referência à naturalização das diferenças de gênero é feita pela presença do material orgânico, como cabelos e insetos. Estas características serão retomadas e ampliadas por outros agrupamentos de objetos no mesmo módulo, que não estão aqui descritos, mas que tratam da apresentação das relíquias familiares (cordões umbilicais, dentes, mechas de cabelos, roupas de bebês, sapatinhos com banhos de metal etc.), dos objetos que desenham a vida familiar como são os álbuns de retratos e dos brinquedos ligados à maternidade. Se o repertório associado ao gênero masculino é formado por objetos de cunho autobiográfico, como pretendemos demonstrar no módulo que sucede o que aqui se discute (Aprendendo o Masculino), os objetos femininos associam a atividade biológica de reprodutora com a função reprodutora da vida social e cultural.

\section{Tabela 2}

\section{Agrupamento 2}

\begin{tabular}{|c|c|c|c|c|c|c|}
\hline \multicolumn{7}{|c|}{ OBJETOS com diferenças de funções, de tecnologia, de morfologia, de épocas, de significados } \\
\hline $\begin{array}{l}\text { Vestidos } \\
\text { com motivos } \\
\text { florais e } \\
\text { foliais. }\end{array}$ & $\begin{array}{l}\text { Arranjos para } \\
\text { cabelo, cha- } \\
\text { péus e leques } \\
\text { com motivos } \\
\text { florais. }\end{array}$ & $\begin{array}{l}\text { Joias com } \\
\text { motivos } \\
\text { florais, fo- } \\
\text { liais, frutas e } \\
\text { insetos feitos } \\
\text { com metais, } \\
\text { cabelos e } \\
\text { insetos. }\end{array}$ & $\begin{array}{l}\text { Toalhas, cor- } \\
\text { tinas, tecidos } \\
\text { de sofá com } \\
\text { motivos flo- } \\
\text { rais e foliais }\end{array}$ & $\begin{array}{l}\text { Objetos } \\
\text { decorativos } \\
\text { em louça na } \\
\text { forma de flo- } \\
\text { res e insetos, } \\
\text { especialmen- } \\
\text { te vasos. }\end{array}$ & $\begin{array}{l}\text { Móveis com } \\
\text { decoração } \\
\text { aplicada na } \\
\text { forma de flo- } \\
\text { res e folhas. }\end{array}$ & \begin{tabular}{|l} 
Cartões \\
postais e fo- \\
tografias em \\
ateliês com \\
mulheres \\
decoradas \\
com flores.
\end{tabular} \\
\hline \multicolumn{7}{|c|}{ SISTEMAS EM QUE ESTÃO INSERIDOS } \\
\hline $\begin{array}{l}\text { Uso feminino. } \\
\text { Vida doméstica } \\
\text { e pública. }\end{array}$ & $\begin{array}{l}\text { Uso feminino. } \\
\text { Vida doméstica } \\
\text { - áreas sociais. } \\
\text { Vida pública. }\end{array}$ & $\begin{array}{l}\text { Uso feminino. } \\
\text { Vida doméstica } \\
\text { - áreas sociais. } \\
\text { Vida pública. }\end{array}$ & $\begin{array}{l}\text { Vida doméstica } \\
\text { - áreas sociais. } \\
\text { Vida pública. }\end{array}$ & $\begin{array}{l}\text { Vida doméstica } \\
\text { - áreas priva- } \\
\text { das e sociais. }\end{array}$ & $\begin{array}{l}\text { Vida doméstica } \\
\text { - áreas priva- } \\
\text { das e sociais. }\end{array}$ & \begin{tabular}{|l} 
Vida \\
doméstica. \\
Vida pública.
\end{tabular} \\
\hline
\end{tabular}


A narrativa museológica, ainda que baseada primordialmente nos objetos, contará com recursos interativos que somará aos resultados das pesquisas já existentes outros originados da análise em curso de acervos importantes para o tema, como é o caso dos anúncios publicitários da loja de departamento Mappin. ${ }^{71}$ Não abriremos mão igualmente de recursos linguísticos utilizados em painéis e legendas, mas que não substituem nem competem com os objetos, apenas acrescentam informações disponíveis sobre as suas biografias e oferecem sínteses das questões apresentadas.

Finalmente, se retornarmos às premissas conceituais brevemente apresentadas no início deste artigo, concluiremos que, assim como a materialidade é intrínseca à vida social, ela o é igualmente ao processo curatorial. O uso que os curadores fazem dos objetos do acervo e a ação que estes objetos têm sobre as práticas curatoriais, determinam a forma de documentação, as tipologias a ser coletadas, a busca em lojas, antiquários, bazares beneficentes, brechós, feiras, residências. Estas rotinas curatoriais se revertem em novas questões de pesquisa e em novas tipologias de acervo. Em um ciclo virtuoso, a curadoria se alimenta da relação com os objetos e estes definem os caminhos da curadoria em um movimento constante que acaba por tornar o museu indissociável de seu acervo.

71 Isabela Ribeiro Arruda, Maiara Henrique Moreira e Osvaldo Bruno Meca Santos da Silva, alunos de graduação, com co-orientação da documentalista Shirley Ribeiro Soares, pesquisam atualmente os anúncios publicitários do Mappin para compor com artistas convidados um conjunto de audiovisuais e interativos que deverão perpassar todas as salas expositivas. 